\title{
Reconstruction of cytosolic fumaric acid biosynthetic pathways in Saccharomyces cerevisiae
}

\author{
Guogiang $X u^{1,2,3}$, Liming Liu ${ }^{1,2,3^{*}}$ and Jian Chen ${ }^{1,2,3^{*}}$
}

\begin{abstract}
Background: Fumaric acid is a commercially important component of foodstuffs, pharmaceuticals and industrial materials, yet the current methods of production are unsustainable and ecologically destructive.

Results: In this study, the fumarate biosynthetic pathway involving reductive reactions of the tricarboxylic acid cycle was exogenously introduced in S. cerevisiae by a series of simple genetic modifications. First, the Rhizopus oryzae genes for malate dehydrogenase (ROMDH) and fumarase (RoFUM1) were heterologously expressed. Then, expression of the endogenous pyruvate carboxylase (PYC2) was up-regulated. The resultant yeast strain, FMME-001 $\uparrow P Y C 2+\uparrow R O M D H$, was capable of producing significantly higher yields of fumarate in the glucose medium (3.18 \pm $0.15 \mathrm{~g}$ iter $^{-1}$ ) than the control strain FMME-001 empty vector.
\end{abstract}

Conclusions: The results presented here provide a novel strategy for fumarate biosynthesis, which represents an important advancement in producing high yields of fumarate in a sustainable and ecologically-friendly manner.

Keywords: Fumaric acid, Saccharomyces cerevisiae, Rhizopus oryzae, RoMDH, RoFUM1, PYC2

\section{Background}

Fumaric acid, a four-carbon dicarboxylic acid, is widely used in modern day industries ranging from materials to human and animal food and therapeutic drugs. Its abilities to be converted into pharmaceutical products and act as starting material for polymerization and esterification reactions have led to the U.S. Department of Energy to designate fumaric acid among the top 12 biomass building-block chemicals with potential to significantly enhance the economy [1]. Fumaric acid is currently produced in large scale by one of three different routes: $(i)$ chemical synthesis; (ii) enzymatic catalysis; and (iii) fermentation. The process of chemical synthesis requires heavy metal catalysts, organic solvents, high temperature and high pressures [2], which makes the conversion of maleic anhydride to fumarate can be ecologically destructive. Enzymatic conversion of maleic anhydride derived from petroleum into fumarate is unsustainable and costly due to the dwindling global supply of petroleum resources and increasing oil prices, despite the fact that a high conversion yield is

\footnotetext{
* Correspondence: mingll@jiangnan.edu.cn; jchen@jiangnan.edu.cn

'State Key Laboratory of Food Science and Technology, Jiangnan University, Wuxi 214122, China

Full list of author information is available at the end of the article
}

achievable [3]. A fermentation process based on fungi, such as Rhizopus oryzae and Rhizopus arrhizus, has been successfully used for fumaric acid production [4]; however, this process is limited on the industrial scale since these fungi are difficult to grow and their morphology can strongly affect production characteristics. Moreover, since these fungi harbor potentially pathogenic properties, product safety is questionable.

The yeast Saccharomyces cerevisiae is a well-established industrial production organism, and is especially known for its outstanding capacity to produce ethanol. This yeast species also possesses good cultivation characteristics, including requiring a simple chemically defined medium, being fairly resistant to inhibitors that are normally present in biomass hydrolysates, and having an extraordinarily robust tolerance for high sugar and ethanol concentrations. In addition, S. cerevisiae's robust tolerance towards acidic conditions represents a major advantage in that it lowers the risk of contamination in industrial fermentation [5]. It is believed that the long history of the safe usage in the food and beverage industry may facilitate and expedite of S. cerevisiae's federal approval for use in the production of organic acids destined for human consumption. 
In addition, this type of yeast is a popular eukaryotic model organism for the study of fundamental biological processes. Its genome has been completely sequenced, and its genetic and physiologic properties are not only well-characterized but established tools of genetic manipulation and screening research strategies [6]. Several databases such as the Saccharomyces Genome Database (SGD) (http://www.yeastgenome.org), have provided an enormous amount of information on $S$. cerevisiae genes, open reading frames, and gene products. Likewise, a multitude of technologies have been developed for high-throughput analysis of the yeast transcriptome, proteome, metabolome, and interactome [7]. Collectively, these features have made yeast a very attractive platform for metabolic engineering. In particular, S. cerevisiae is being investigated for its capacity for large-scale biotechnological production of organic acids. Indeed, some progress has been made in exploring the utility of metabolic engineering of $S$. cerevisiae, and it has been successfully manipulated to produce monocarboxylic acid pyruvate [8], lactate [9], dicarboxylic acid malate $[10,11]$, and succinate [2].

Despite these advances, metabolic engineering of $S$. cerevisiae for the production of biotechnologically interesting carboxylic acids from renewable feedstocks remains to be optimized [12]. S. cerevisiae in its natural state cannot accumulate large amounts of fumarate in the cytosol, due to the fact that cytosolic fumarase catalyzes the conversion of fumarate to L-malate but not vice versa [13]. Stein and colleagues have demonstrated that a single translation product of the FUM1 gene that encodes fumarase is distributed between the cytosol and mitochondria in S. cerevisiae [14]. Many studies have since concentrated on elucidating the mechanism underlying this post-translation distribution profile [15-18]. Surprisingly, no reports in the literature have described attempts to up-regulate fumarase via metabolic engineering approaches in order to increase fumarate accumulation in S. cerevisiae.

We considered that fumarate can be accumulated and excreted by $R$. oryzae through reductive reactions of the tricarboxylic acid cycle $[19,20]$, and asked whether $S$. cerevisiae can accumulate fumarate by a completely cytosolic fumarate biosynthetic pathway. Therefore, we sought to develop a novel metabolic pathway for fumarate production in $S$. cerevisiae by introducing the follow genetic improvements (Figure 1): (i) heterologous expression of cytosolic $R$. oryzae malate dehydrogenase; (ii) high-level expression of the $R$. oryzae fumarase; and (iii) over-expression of the native cytosolic pyruvate carboxylase encoded by PYC2. In addition, we evaluated which protein represents the limiting factor for fumarate formation.

\section{Results}

Comparative analysis of two species malate dehydrogenases on fumarate production capabilities

Over-expression of malate dehydrogenase in the cytosol of $S$. cerevisiae was achieved by two methods. In the first, endogenous malate dehydrogenase was overexpressed. One of the three malate dehydrogenase isoenzymes in $S$. cerevisiae, Mdh2p, is known to be subject to glucose catabolite inactivation [21] even though it is located in the cytosol, ultimately limiting batch cultivation on glucose. Therefore, the strategy selected for cytosolic malate dehydrogenase overexpression was based on re-targeting Mdh3 by removing the C-terminal SKL tripeptide [22]. In the second, the heterologous RoMDH gene was overexpressed. The corresponding engineered strains, FMME-001 $\uparrow M D H 3 \triangle S K L$ and FMME-001 $\uparrow R o M D H$, were evaluated for the titers of fumarate produced. FMME-001 $\uparrow M D H 3 \triangle S K L$ achieved an average of $0.44 \pm$ 0.03 g liter $^{-1}$, while FMME-001 $\uparrow R o M D H$ achieved an average of $0.54 \pm 0.04 \mathrm{~g} \mathrm{liter}^{-1}$ (Figure 2). These results indicated that the FMME-001 $\uparrow$ RoMDH strain had a $22.7 \%$ higher fumarate yield than the strain FMME-001 $\uparrow M D H 3 \triangle S K L$ strain. Moreover, the higher $\mathrm{Y}_{\mathrm{P} / \mathrm{S}}$ value associated with the FMME-001 $\uparrow$ RoMDH strain led us to focus our subsequent studies on the cytosolic malate dehydrogenase encoded by the RoMDH.

\section{Fumaric acid characterization}

The Fourier transform infrared (FT-IR) spectra of sample isolated from the fermentation broth of our engineered strain was consistent with the fumaric acid standard (Figure 3). In addition, the ${ }^{1} \mathrm{H}$ NMR spectra and ${ }^{13} \mathrm{C}$ NMR spectra showed excellent matches between the sample and fumaric acid standard (Figure 4). Thus, these results confirmed that fumaric acid was, in fact, synthesized by our engineered $S$. cerevisiae strain.

\section{Effects of RoMDH and RoFUM1 co-expression on fumarate production}

In order to augment the fumarate synthesis ability of FMME-001 $\uparrow R o M D H$, the $R$. oryzae RoFUM1 gene encoding cytosolic fumarase was simultaneously overexpressed from a high copy vector. However, the coexpression strain FMME-001 $\uparrow$ RoMDH $+\uparrow R o F U M 1$ did not exhibit a significantly higher titer of fumarate as expected; instead, the titer decreased to $0.38 \pm 0.03 \mathrm{~g}$ liter $^{-1}$, and slightly more malic acid, citric acid, and succinic acid were detected (Table 1).

\section{Fumarate synthesis pathway enzyme activities and transcriptional levels}

To elucidate the molecular mechanism underlying the low titer of fumarate accumulation in the cytosol of the 


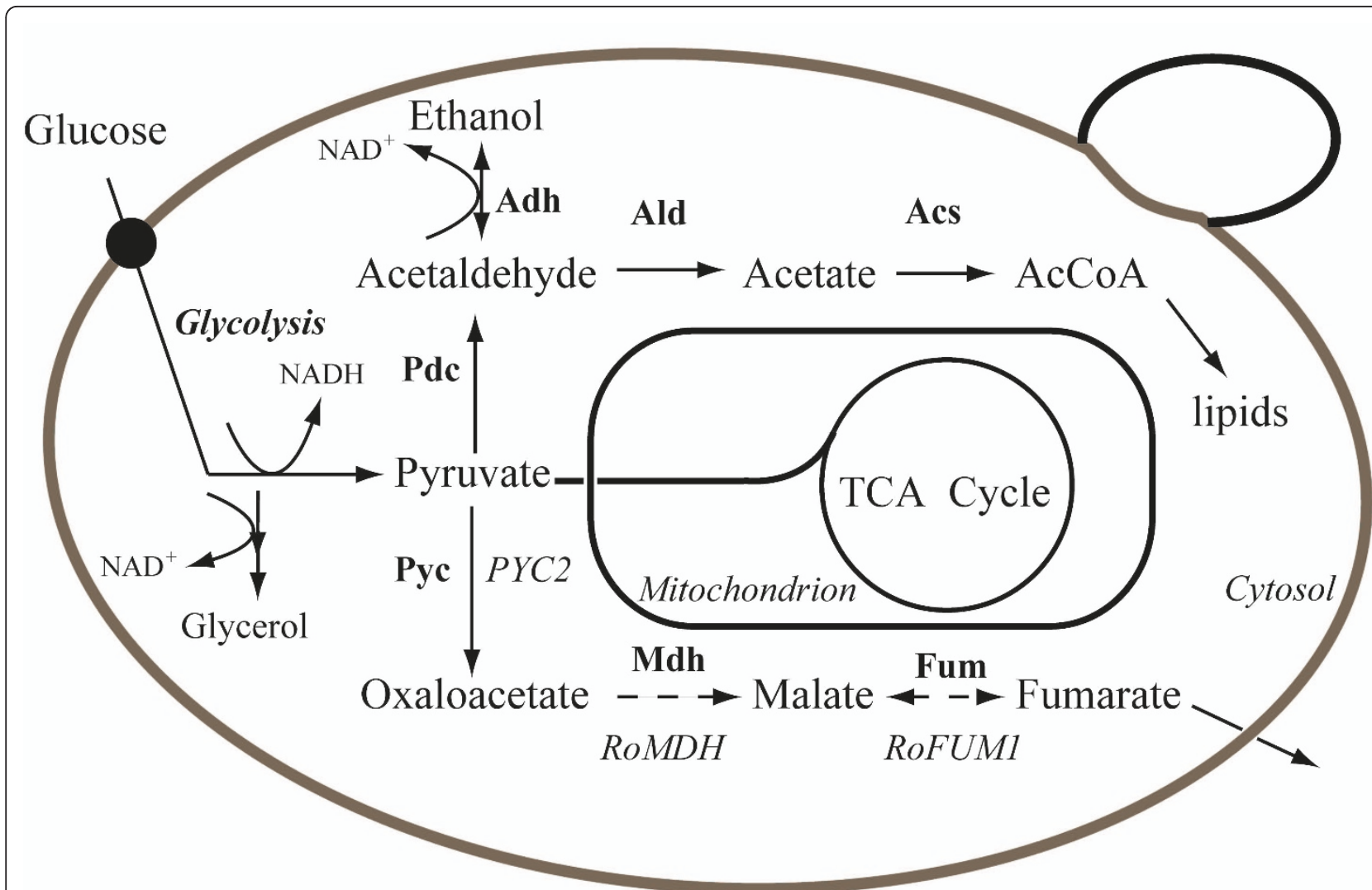

Figure 1 The cytosolic fumarate biosynthetic pathway in S. cerevisiae. Abbreviations of enzymes: Pyc, pyruvate carboxylase; Mdh, malate dehydrogenase; Fum, fumarase; Pdc, pyruvate decarboxylase; Adh, alcohol dehydrogenase; Ald, acetaldehyde dehydrogenase; Acs, acetyl-CoA synthetase.

engineered yeast strain FMME-001 $\uparrow$ RoMDH + $\uparrow$ RoFUM1, the activity and transcriptional level of key enzymes in the fumarate synthesis pathway were determined. The specific activity of malate dehydrogenase was found to be $40.5 \pm 4.3 \mathrm{U} \mathrm{min}^{-1}$ (mg protein) ${ }^{-1}$, approximately 18 -fold higher than that of the control strain $\left(2.2 \pm 0.31 \mathrm{Umin}^{-1}(\mathrm{mg} \text { protein })^{-1}\right)$. In addition, the specific activity of fumarase was only $0.030 \pm 0.002$ $\mathrm{U} \mathrm{\operatorname {min } ^ { - 1 }}$ (mg protein) $)^{-1}$, while the activity of the reverse reaction was $0.140 \pm 0.010 \mathrm{U} \mathrm{min}^{-1}(\mathrm{mg} \text { protein })^{-1}$. Pyruvate carboxylase activity of FMME-001 $\uparrow$ RoMDH + $\uparrow$ RoFUM 1 was only $0.0022 \pm 0.0002 \mathrm{U} \mathrm{min}^{-1}$ (mg protein $)^{-1}$ (Table 2). The gene expression levels of $R o M D H$ and RoFUM1 were dramatically increased, as detected by quantitative real-time PCR (QT-PCR) (Figure 5A). Taken together, these results suggest that pyruvate carboxylase represents the rate limiting factor of fumarate production.

\section{Effects of over-expression of endogenous pyruvate carboxylase}

The integration-expression of $P Y C 2$ in the engineered strain FMME-001 $\uparrow R o M D H$ resulted in increased specific activity of pyruvate carboxylase by $20.8 \%(P<$ $0.05, \mathrm{n}=3)$. Consequently, the fumarate titer also increased by a remarkable $488.9 \%$ (from $0.54 \pm 0.04 \mathrm{~g}$ liter $^{-1}$ to $\left.3.18 \pm 0.15 \mathrm{~g} \mathrm{liter}^{-1}\right)$, as compared to the control strain FMME-001 (Table 1).

\section{Discussion}

S. cerevisiae is an important industrial tool and biological model. Although this particular yeast species does not typically excrete a high titer of organic acids, its high metabolic capacity makes it a potential promising platform for engineered organic acid production. In order to establish this type of system, however, heterologous metabolic pathways must be introduced and optimized to facilitate the conversion of sugars to organic acids. The study described herein set about to accomplish the heterologous introduction of a cytosolic fumarate biosynthetic pathway into $S$. cerevisiae via genetic engineering; ultimately, this simple manipulation achieved $3.18 \pm 0.15 \mathrm{~g}$ liter $^{-1}$ fumarate production. Indeed, the level of fumarate achieved by this engineered strain was low as compared with that from $R h i$ zopus oryzae or Rhizopus arrhizus. The most likely 

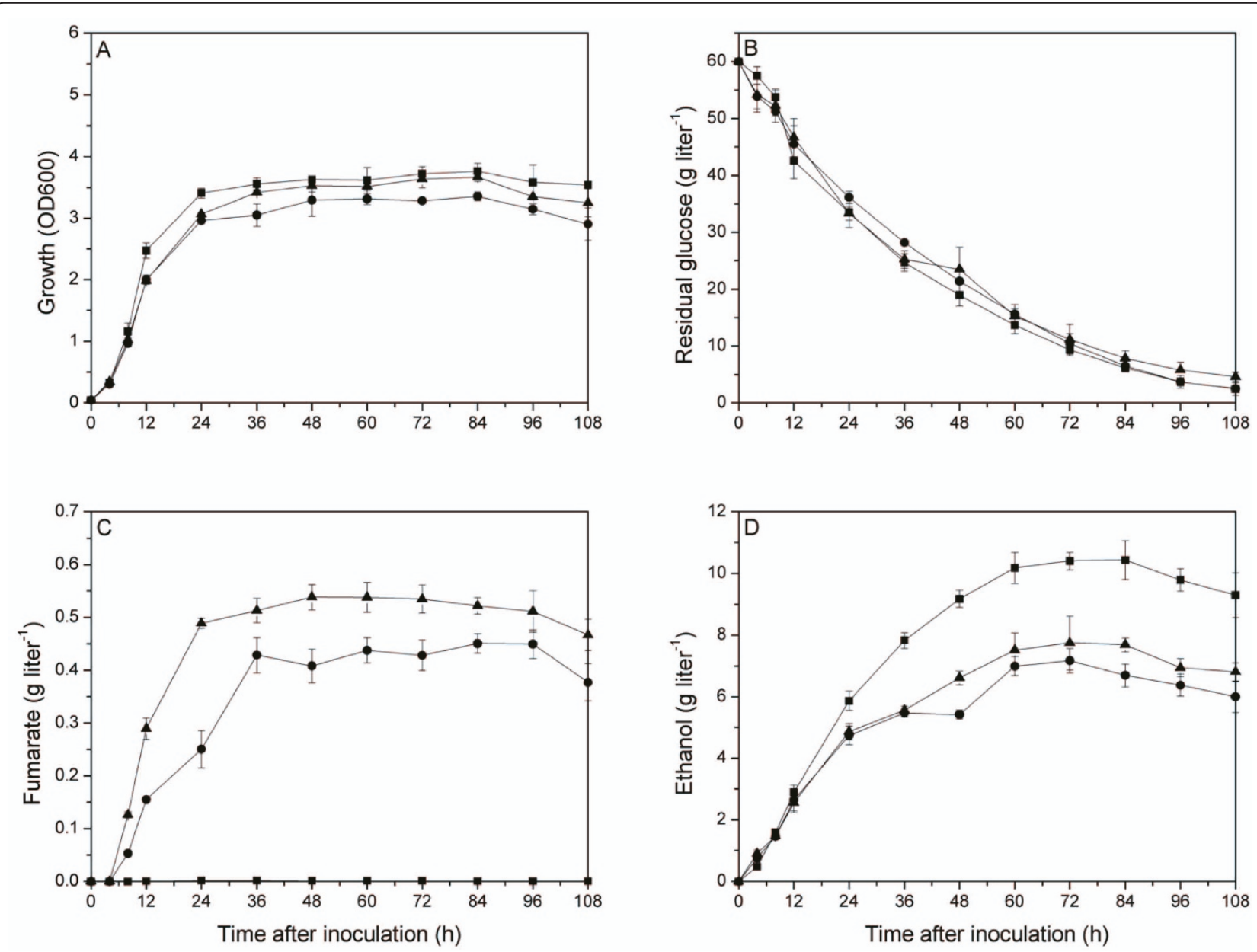

Figure 2 Fermentation profile for cell growth, glucose utilization and product accumulation during aerobic batch cultures of control strain FMME-001 empty vector, engineered strains FMME-001 $\uparrow M D H 3 \triangle S K L$ and FMME-001 $\uparrow$ RoMDH with $6 \%$ glucose. A: growth, B: residual glucose, C: fumaric acid and D: ethanol. Symbols: square, FMME-001 empty vector, circle, FMME-001 $\uparrow M D H 3 \triangle S K L$, triangle, FMME-001 $\uparrow R O M D H$. Error bars indicate standard deviation $(n=3)$.

reasons for this, and focus of our future studies to improve the S. cerevisiae-based method, are as follows:

A novel metabolic pathway for fumarate production was established in S. cerevisiae; this series of chemical reactions began with carboxylation of pyruvate to oxaloacetate, followed by reduction to malate, and finally reduction to fumarate (Figure 1). Flux through the cytosolic fumarate biosynthetic pathway is principally determined by the abundance and biochemical properties of three enzymes in the fumarate biosynthetic pathway, transporters, and regulatory proteins, as well as their interactions with each other and the metabolites generated by each.

A previous study had demonstrated that over-expression of a truncated form of $M D H 3(M D H 3 \triangle S K L)$, which remained sequestered in the cytosol, led to a more than 20-fold increase in cytosolic malate dehydrogenase activity [10]. Meanwhile, an unrelated study found that $R$. oryze had naturally occurring high activities of cytosolic malate dehydrogenase (encoded by the gene RoMDH) corresponding with fumarate production [19]. Furthermore, a higher titer and yield of fumarate was achieved when RoMDH was overexpressed in S. cerevisiae. Together, these findings indicated that the cytosolic malate dehydrogenase encoded by the RoMDH gene was a potential candidate for further biological manipulation to enhance fumarate production. Moreover, a relatively higher activity of fumarase was reported in $R$. oryzae $[19,20]$. Contrary to expectations, however, when RoFUM1 was heterologously expressed in S. cerevisiae, the fumarate titer decreased and the malate titer increased, presumably due to the fact that the RoFUM1encoded fumarase has about 4.5-fold higher affinity for fumarate than for L-malate [19]. Subsequently, our evaluations of the enzyme activity revealed that the malate dehydrogenase activity was significantly increased in the 


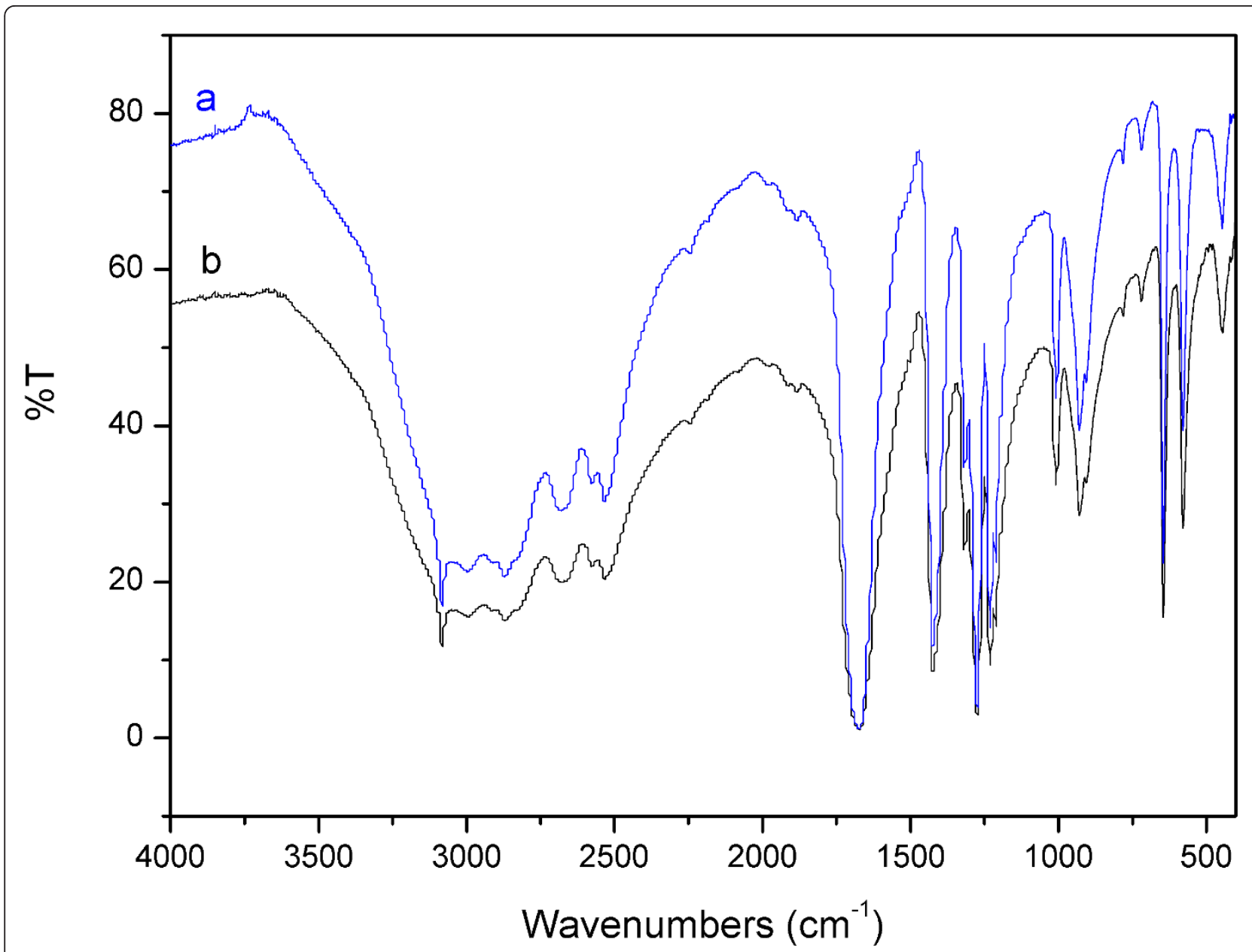

Figure $\mathbf{3}$ The IR spectra of fumaric acid. (a) sample, (b) the fumaric acid standard.

engineered strain, as compared to that in the parent strain, and only very low levels of pyruvate carboxylase were detectable in the engineered strain FMME-001 $\uparrow R o M D H$. Furthermore, comparative analysis of the RoMDH and RoFUM1 transcripts demonstrated that both genes were significantly up-regulated. Collectively, these results suggest that pyruvate carboxylase has a relatively low degree of control over the rate of fumarate production in the engineered strain FMME-001 $\uparrow R o M D H$.

With the integrated-expression of the $P Y C 2$ gene in $S$. cerevisiae the titer of fumarate increased from $0.54 \pm$ $0.02 \mathrm{~g}$ liter $^{-1}$ to $3.18 \pm 0.15 \mathrm{~g} \mathrm{liter}^{-1}$. Quantitative realtime PCR analysis showed that a small increase in the transcriptional level of $P Y C 2$ had occurred after $P Y C 2$ integrated-expression $(70.2 \%, P<0.05, \mathrm{n}=3$ ) (Figure $5 \mathrm{~B})$. This result indicated that pyruvate carboxylase is able to control the carbon flux conduit towards fumarate in the engineered strain. This finding was consistent with the hypothesis that $\mathrm{C} 4$ dicarboxylic acids require large fluxes through the carboxylating anaplerotic pathways to achieve particularly high yield [12]. Furthermore, over-expression of the native $P Y C 2$ gene in $S$. cerevisiae is known to elicit a higher specific malate production due to increased carboxylation of pyruvate to oxaloacetate [10].

In this study, $6.53 \pm 0.63 \mathrm{~g} \mathrm{liter}^{-1}$ ethanol and $1.65 \pm$ $0.14 \mathrm{~g}$ liter $^{-1}$ glycerol were detected in the fermentation broth of FMME-001 $\uparrow P Y C 2+\uparrow R o M D H$ (Table 1). This phenomenon is known as "overflow metabolism". In $S$. cerevisiae, overflow metabolism begins when the specific glucose uptake rate (or the glycolytic flux) exceeds a threshold rate, resulting in the formation of ethanol and glycerol [23]. Thus, in order to further increase fumarate accumulation it is necessary to develop a metabolicengineering strategy to reduce or eliminate ethanol formation.

This goal can be achieved by disrupting or weakening the specific enzymes, such as pyruvate decarboxylase and alcohol dehydrogenase $[8,24]$, or by manipulating 


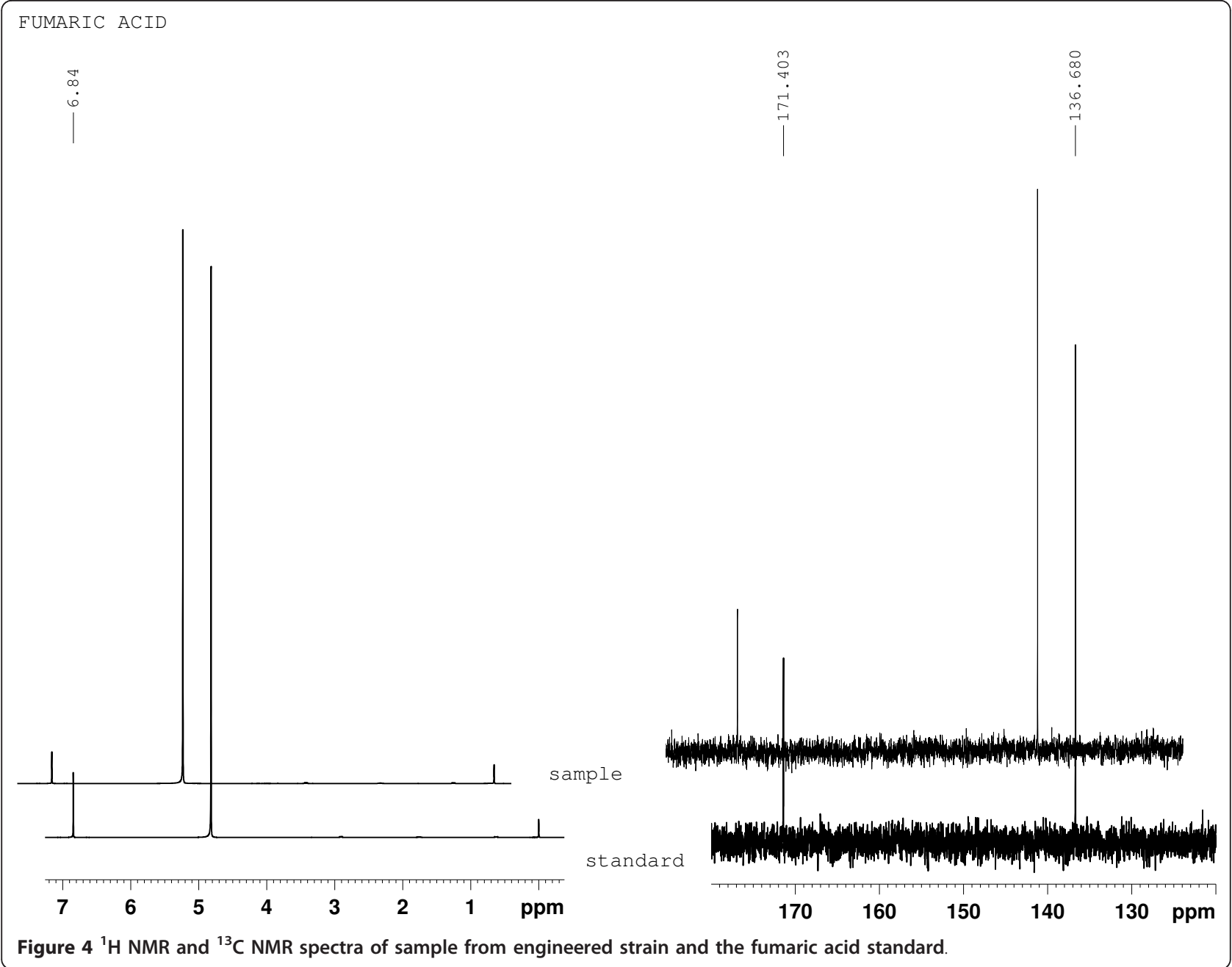

the available concentration of thiamine that is required by pyruvate decarboxylase [25]. Meanwhile, increasing the direct oxidation of $\mathrm{NADH}$, either by enhancing respiration via improvements in the dissolved oxygen content or by overexpressing an alternative oxidase [23], is also an effective approach to reduce ethanol production.

\section{Conclusions}

In this study, we sought to explore the feasibility of $S$. cerevisiae as a metabolically-engineered platform to

Table 1 Shake flask cultivation characteristics of cell growth, glucose utilization, and production of fumarate, pyruvate, ethanol, glycerol and some other metabolites of the TCA cycle

\begin{tabular}{|c|c|c|c|c|}
\hline Strain & FMME-001 empty vector & FMME-001 $\uparrow R O M D H$ & FMME-001 $\uparrow R o M D H+\uparrow R o F U M 1$ & FMME-001 $\uparrow P Y C 2+\uparrow R o M D H$ \\
\hline Glucose consumption (g liter ${ }^{-1}$ ) & 48 & 48 & 48 & 48 \\
\hline Biomass (OD600) & $3.58( \pm 0.28)$ & $3.23( \pm 0.22)$ & $2.98( \pm 0.14)$ & $3.70( \pm 0.19)$ \\
\hline Ethanol (g liter ${ }^{-1}$ ) & $10.40( \pm 0.35)$ & $7.74( \pm 0.43)$ & $7.41( \pm 0.37)$ & $6.53( \pm 0.63)$ \\
\hline Glycerol (g liter ${ }^{-1}$ ) & $1.58( \pm 0.12)$ & $1.40( \pm 0.13)$ & $1.34( \pm 0.12)$ & $1.65( \pm 0.14)$ \\
\hline Pyruvic acid (g liter $\left.{ }^{-1}\right)$ & $0.32( \pm 0.015)$ & $0.42( \pm 0.018)$ & $0.41( \pm 0.056)$ & $0.26( \pm 0.011)$ \\
\hline Fumaric acid (g liter $\left.{ }^{-1}\right)$ & $<0.00( \pm 0.00)$ & $0.54( \pm 0.04)$ & $0.38( \pm 0.03)$ & $3.18( \pm 0.15)$ \\
\hline Malic acid (g liter ${ }^{-1}$ ) & $0.18( \pm 0.02)$ & $0.72( \pm 0.06)$ & $0.80( \pm 0.06)$ & $0.66( \pm 0.07)$ \\
\hline Citric acid (g liter ${ }^{-1}$ ) & $0.056( \pm 0.003)$ & $0.068( \pm 0.005)$ & $0.076( \pm 0.004)$ & $0.057( \pm 0.003)$ \\
\hline$\alpha$-Ketoglutarate (g liter ${ }^{-1}$ ) & $0.027( \pm 0.002)$ & $0.033( \pm 0.003)$ & $0.030( \pm 0.002)$ & $0.064( \pm 0.008)$ \\
\hline Succinic acid (g liter $\left.{ }^{-1}\right)$ & $0.016( \pm 0.002)$ & $0.012( \pm 0.002)$ & $0.018( \pm 0.003)$ & $0.060( \pm 0.004)$ \\
\hline
\end{tabular}


Table 2 Comparison of the activities of key enzymes activities in the control strain and engineered strain

\begin{tabular}{|c|c|c|c|c|}
\hline \multirow[t]{2}{*}{ Strain $^{a}$} & \multicolumn{4}{|c|}{ Enzyme activity ${ }^{b}\left(\mathrm{U} \mathrm{min}^{-1}(\mathrm{mg} \text { protein })^{-1}\right)$ of: } \\
\hline & $\mathrm{MDH}$ & FUM, malate to fumarate & FUM, fumarate to malate & PYC \\
\hline Reference & $2.2 \pm 0.31$ & $0.002 \pm 0.000$ & $0.021 \pm 0.002$ & $0.0022 \pm 0.0002$ \\
\hline FMME-001 $\uparrow R O M D H+\uparrow R O F U M 1$ & $40.5 \pm 4.3$ & $0.030 \pm 0.002$ & $0.140 \pm 0.010$ & $0.0022 \pm 0.0002$ \\
\hline Ratio & 18.41 & 15.0 & 6.67 & 1.00 \\
\hline
\end{tabular}

${ }^{a}$ Yeast strains were grown in shake flasks on glucose medium, unless otherwise indicated in the text.

${ }^{b} \mathrm{MDH}$, malate dehydrogenase; FUM, fumarase; PYC, pyruvate carboxylase. Errors represent deviations from the means (for each condition, $\mathrm{n}=3$ ).

safely and effectively produce high yields of fumarate by using a completely cytosolic fumarate biosynthetic pathway. Previous studies had indicated that cytosolic malate dehydrogenase encoded by the $R o M D H$ gene is more effective than that encoded by the $M D H 3 \triangle S K L$ gene, and that pyruvate carboxylase represents the rate limiting factor of fumarate production. To the best of our knowledge, the study described herein is the first to demonstrate $S$. cerevisiae as a useful host strain for synthesizing fumarate by introducing genes from $R$. ory$z a e$. This study not only provides a novel and environmentally-friendly method of producing fumaric acid, but also suggests strategies to further improve the fumarate yield in future researches.

\section{Methods}

Yeast strains and maintenance

All yeast strains used in this study were derived from $S$. cerevisiae BMA64 (MATa/MAT $\alpha$ ura3-52/ura3-52; $\operatorname{trp} 1 \Delta 2 / \operatorname{trp} 1 \Delta$ 2; leu2-3,112/leu2-3,112; his3-11/his3-11; ade2-1/ade2-1; can1-100/can1-100; from Euroscarf, Frankfurt, Germany) (Table 3). Stock cultures were prepared by adding glycerol $(25 \% \mathrm{vol} / \mathrm{vol})$ to shake flask cultures (detailed below); aliquots $(1 \mathrm{ml})$ were placed in sterile vials and stored at $-80^{\circ} \mathrm{C}$ until use.

\section{Isolation of the fumarate-biosynthesis genes}

R. oryzae NRRL1526 (ATCC 10260) was cultured in fermentation medium until the acid production phase was reached, then the fungus was harvested by centrifugation and snap frozen in liquid nitrogen for storage at $-80^{\circ} \mathrm{C}$ until use. Total RNA was extracted by RNAprep pure Plant Kit (Tiangen Biotech Co., Ltd., Beijing, China), according to the manufacturer's protocol. Poly $(\mathrm{A})^{+} \mathrm{mRNA}$ was purified from total RNA using Oligo(dT) 15 primer in accordance with the manufacturer's instruction, then mRNA were used for cDNA synthesis by means of the Quantscript RT Kit (Tiangen Biotech Co., Ltd.).

The PCR primer pairs covering the entire open reading frame (ORF) of these two genes were designed according to the GenBank sequences of $R$. oryzae using the Primer Premier v5.0 software (Table 4). Thermal cycling parameters comprised an initial denaturation step at $94^{\circ} \mathrm{C}$ for $5 \mathrm{~min}$, followed by 29 cycles of denaturation at $94^{\circ} \mathrm{C}$ for $30 \mathrm{~s}$, annealing at $52^{\circ} \mathrm{C}$ for $30 \mathrm{~s}$, and extension at $72^{\circ} \mathrm{C}$ for $1 \mathrm{~min} / \mathrm{kb}$, with a final single extension step at $72^{\circ} \mathrm{C}$ for $10 \mathrm{~min}$. The reactions were carried out in a $\mathrm{C} 1000^{\mathrm{TM}}$ Thermal Cycler instrument (Bio-Rad, USA). Thereafter, a 1485-bp fragment of the RoFUM1 gene and a 1014-bp fragment of the RoMDH gene were amplified by nested PCR. The sequences of
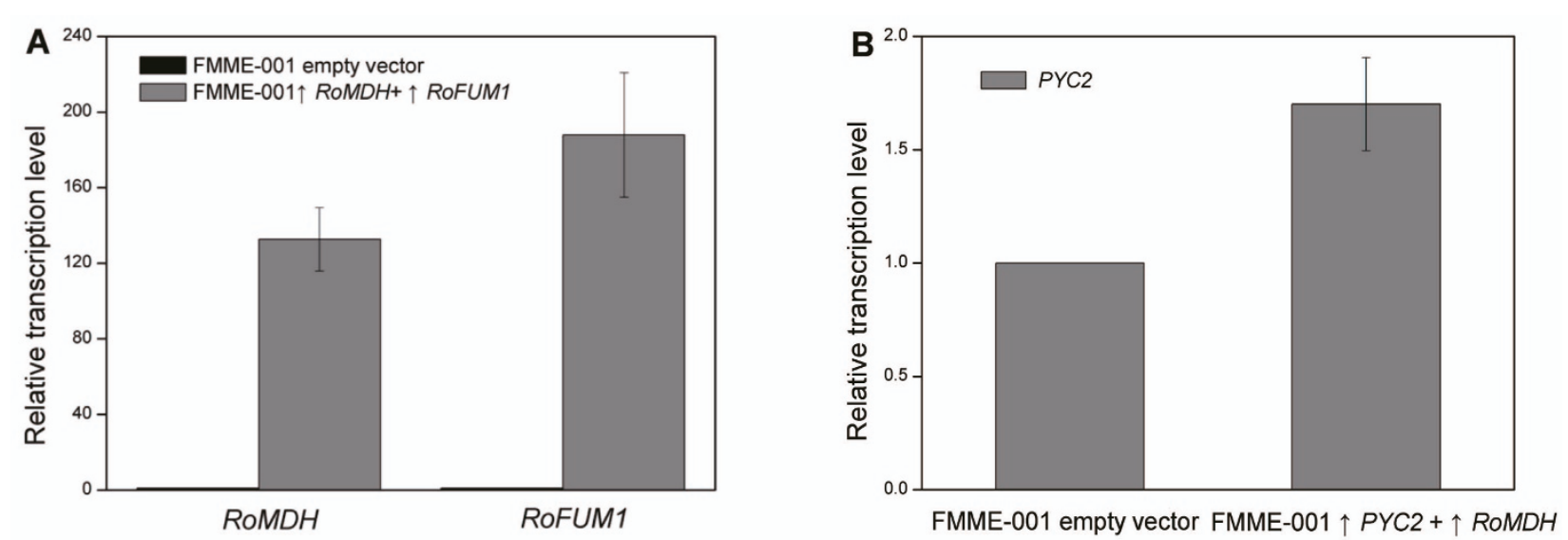

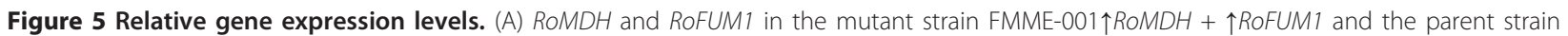
FMME-001 empty vector. Relative gene expression level of (B) PYC2 in the mutant strain FMME-001 $\uparrow P Y C 2+\uparrow R O M D H$ and the parent strain FMME-001 empty vector. Relative transcription levels were normalized to the transcription level of the $\beta$-ACTIN gene, which was taken as 1 . The presented values are averages of three independent experiments; the error bars indicate standard deviations. 
Table 3 Plasmids and strains used in this study

\begin{tabular}{|c|c|c|}
\hline Plasmids or strains & Genotype or description & Source or reference \\
\hline \multicolumn{3}{|l|}{ Plasmids } \\
\hline pY26 TEF/GPD & $2 \mu \mathrm{m} U R A 3, \mathrm{P}_{\mathrm{GPD}} / T_{\mathrm{CYC} 1}, \mathrm{P}_{\mathrm{TEF}} / \mathrm{T}_{\mathrm{ADH} 1}$ & Lab collection \\
\hline pRS305TEF & integration vector $L E U 2, \mathrm{P}_{\mathrm{TEF} 1} / \mathrm{T}_{\mathrm{ADH} 1}$ & [26] \\
\hline \multicolumn{3}{|l|}{ S. cerevisiae strains } \\
\hline BMA64 & MATa/MAT $\alpha$; reference strain & Euroscarf \\
\hline FMME-001 empty vector & MATa/MAT $\alpha\{\mathrm{pY} 26 \mathrm{TEF} / \mathrm{GPD}\}$ & This study \\
\hline FMME-001 $\uparrow M D H 3 \triangle S K L$ & 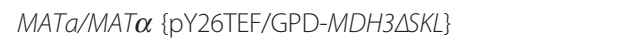 & This study \\
\hline FMME-001 $\uparrow R O M D H$ & MATa/MAT $\alpha\{\mathrm{pY} 26 \mathrm{TEF} / \mathrm{GPD}-\mathrm{ROMDH}\}$ & This study \\
\hline FMME-001 $\uparrow R O M D H+\uparrow R O F U M 1$ & MATa/MAT $\alpha$ \{pY26TEF-RoFUM1/GPD-RoMDH\} & This study \\
\hline FMME-001 $\uparrow P Y C 2+\uparrow R O M D H$ & MATa/MAT $\alpha$ \{pRS305TEF1-PYC2, pY26TEF/GPD- RoMDH\} & This study \\
\hline
\end{tabular}

these two gene fragments were submitted to GenBank under accession numbers HM130701 (RoFUM1) and HM130702.1 (RoMDH), and their nucleotide sequence alignments showed high identity (99.7\% for RoFUM1; 95.6\% for $\mathrm{RoMDH}$ ).

\section{Construction of the plasmids}

The plasmids used in this study are listed in Table 3. Gene-specific primers (Table 4) were designed to amplify RoMDH, RoFUM, MDH3 $S K L$ and PYC2. The RoMDH and RoFUM1 genes were amplified by PCR using the cDNA of $R$. oryzae NRRL1526 as template. Both the resultant PCR fragment of $R o M D H$ and expression vector pY26TEF-GPD were digested with BamHI and HindIII sites and ligated together to create pY26TEF-GPD-RoMDH. Then, the PCR product of RoFUM1 and pY26TEF-GPD-RoMDH were digested with NotI and BglII and ligated together to create the pY26TEF-RoFUM1-GPD-RoMDH plasmid.

The $S$. cerevisiae $M D H 3 \triangle S K L$ gene was amplified by PCR from chromosomal DNA of BMA64-1A (MATa leu2-3,112 his3-11,15 trp1s can1-100 ade2-1 ura3-1) using the primers BamHI-F $(M D H 3 \triangle S K L)$ and HindIII-R
$(M D H 3 \triangle S K L)$. The resulting fragment contains the entire $M D H 3$ gene minus the last 9 base pairs that encode the peroxisomal targeting sequence (the tripeptide SKL). The PCR fragment and pY26TEF-GPD vector were digested with BamHI and SalI and ligated to create pY26TEFGPD-MDH3 $\triangle S K L$. The gene coding for $S$. cerevisiae pyruvate carboxylase, $P Y C 2$, was also amplified by PCR from chromosomal DNA of BMA64-1A but using the primers PstI-F(PYC2) and SalI-R(PYC2). The PCR fragment and pRS305TEF1 vector were digested with PstI and SalI and ligated to create pRS305TEF1-PYC2.

\section{Yeast transformation}

DNA was introduced into yeast cells using a Frozen-EZ Yeast Transformation II kit (Zymo Research, Orange, CA, USA), according to the recommended protocol. The transformants were selected on agar plates of Synthetic Complete (SC) Selection medium lacking specific amino acid or pyrimidine for the auxotrophic markers.

\section{Shake flask cultivation}

Shake flask cultures were grown on fermentation medium containing (per liter): demineralized water, $60 \mathrm{~g}$

Table 4 Primers used in this study for gene cloning and plasmid construction

\begin{tabular}{|c|c|c|}
\hline Oligonucleotides & Sequences, 5'-3' & Usage \\
\hline F-RoFUM1 & ATGTTGCGAGCTTCTGCTACC & Cloning of RoFUM1 \\
\hline R-RoFUM1 & TTAATCCTTGGCAGAGATCATATCTT & \\
\hline $\mathrm{F}-\mathrm{ROMDH}$ & ATGTTTGCCGCCTCTCGTG & Cloning of $\mathrm{ROMDH}$ \\
\hline $\mathrm{R}-\mathrm{RoMDH}$ & TTATTGAACAAAGCTGTTACCCTTG & \\
\hline BamHI-F(RoMDH) & CGGGATCCATGTTGCCGCCTCTCGTG & Construction of pY26TEF-GPD-RoMDH \\
\hline HindIII-R(ROMDH) & CCCAAGCTITATTGAACAAAGCTGTTACCCTTG & \\
\hline BamHI-F(MDH3 $\triangle S K L)$ & CGGGATCCATGGTCAAAGTCGCAATTCTTG & Construction of pY26TEF-GPD- MDH3 $\triangle S K L$ \\
\hline HindIII-R(MDH3 $\triangle S K L)$ & CCCAAGCTITCAAGAGTCTAGGATGAAACTCTTGCCT & \\
\hline Notl-F(RoFUMT) & ATAAGAATGCGGCCGCATGTTGCGAGCITCTGCTACC & Construction of pY26TEF- RoFUM1-GPD- ROMDH \\
\hline $\mathrm{Bg} \mid \mathrm{II}-\mathrm{R}(\mathrm{RoFUM})$ & GAAGATCTITAATCCTTGGCAGAGATCATATCTT & \\
\hline Pstl -F(PYC2) & AACTGCAGATGAGCAGTAGCAAGAAATTGGC & Construction of pRS305TEF1-PYC2 \\
\hline Sall $-R(P Y C 2)$ & ACGCGTCGACTTACTIIITGGGATGGGGGT & \\
\hline
\end{tabular}

Abbreviations: $F$, forward; $R$, reverse. Underlined sequences indicate the recognition sites for the indicated restriction enzymes. 
glucose, $2 \mathrm{~g} \mathrm{CO}\left(\mathrm{NH}_{2}\right)_{2}, 5 \mathrm{~g} \mathrm{KH}_{2} \mathrm{PO}_{4}$, and $0.8 \mathrm{~g}$ $\mathrm{MgSO}_{4} \cdot 7 \mathrm{H}_{2} \mathrm{O} \cdot \mathrm{CaCO}_{3}$ (dry-heat sterilized at $160^{\circ} \mathrm{C}$ for $30 \mathrm{~min}$ ) was used as a $\mathrm{pH}$ buffer of the medium. Prior to use, the medium $\mathrm{pH}$ was set to 5.5 with $\mathrm{NaOH}$ and heat sterilized for $20 \mathrm{~min}$ at $115^{\circ} \mathrm{C}$. After cooling, the corresponding filter-sterilized amino acid mix, uracil, and adenine were added. The shake flask technique was performed at $30^{\circ} \mathrm{C}$ in an orbital shaker at $200 \mathrm{rpm}$. The seed medium consisted of (per liter): $20 \mathrm{~g}$ glucose, $1.7 \mathrm{~g}$ Yeast Nitrogen Base (without amino acids or ammonium sulfate), and $5 \mathrm{~g}\left(\mathrm{NH}_{4}\right)_{2} \mathrm{SO}_{4}$. The medium $\mathrm{pH}$ was adjusted to 5.5 with $\mathrm{NaOH}$. The seed culture was inoculated with well-grown yeast on an agar slant and incubated for $24 \mathrm{~h}$ in a $250 \mathrm{ml}$ flask containing $20 \mathrm{ml}$ seed medium. Then, the broth was centrifuged, the pellet was resuspended in isometric fresh fermentation medium, and the cell suspension was inoculated into a $250 \mathrm{ml}$ shake flask containing $50 \mathrm{ml}$ fermentation medium. All experiments were carried out in triplicate.

\section{Metabolite analysis}

Cell growth was determined by measuring the $\mathrm{OD}_{600}$ after desired dilution. Extracellular concentrations of fumarate, ethanol, glycerol and glucose were determined by high performance liquid chromatography, using an Aminex HPX-87H column (Bio-Rad, Hercules, CA, USA) eluted with $0.0275 \%(\mathrm{v} / \mathrm{v}) \mathrm{H}_{2} \mathrm{SO}_{4}$ at a flow rate of $0.6 \mathrm{ml} \mathrm{min}^{-1}$ at $35^{\circ} \mathrm{C}$. Fumarate was detected with Agilent (Santa Clara, CA, USA) 1100 series VWD detector at $210 \mathrm{~nm}$. Ethanol, glycerol and glucose were detected with an 1100 series Agilent refractive index detector.

\section{Confirmation of fumaric acid biosynthesis by $\mathrm{FT}-\mathrm{IR},{ }^{1} \mathrm{H}$ NMR, and ${ }^{13} \mathrm{C}$ NMR}

Cell cultures of the engineered strain were centrifuged and the harvested supernatent adjusted to $\mathrm{pH} 1.0$ by addition of $\mathrm{HCl}$. Following acidification, the fumaric acid precipitated out of the solution and was recovered by drying in a rotary dryer. The obtained sample was processed, along with the fumaric acid standard sample, for FT-IR, ${ }^{1} \mathrm{H}$ NMR, and ${ }^{13} \mathrm{C}$ NMR analyses. The FT-IR spectra were recorded on a Nicolet Nexus 470 spectrophotometer with a DTGS detector. ${ }^{1} \mathrm{H}$ NMR $(400 \mathrm{MHz}$, $\mathrm{D}_{2} \mathrm{O}, 25^{\circ} \mathrm{C}$ ) and ${ }^{13} \mathrm{C}$ NMR $\left(100 \mathrm{MHz}, \mathrm{D}_{2} \mathrm{O}, 25^{\circ} \mathrm{C}\right)$ spectra were recorded on an Avance III $400 \mathrm{MHz}$ digital NMR spectrometer.

\section{Enzyme assays}

The strains were cultivated in fermentation medium containing $60 \mathrm{~g} \mathrm{liter}^{-1}$ glucose. The assay mixture for malate dehydrogenase contained $0.1 \mathrm{M}$ potassium phosphate buffer ( $\mathrm{pH}$ 8.0) and $0.15 \mathrm{mM} \mathrm{NADH}$ in demineralized water. The reaction was started by the addition of $1 \mathrm{mM}$ oxaloacetate. Malate dehydrogenase activity was measured spectrophotometrically by monitoring NADH oxidation at $340 \mathrm{~nm}$.

The pyruvate carboxylase activity was measured by the method described by de Jong-Gubbels, P [27]. The reaction mixture $(1 \mathrm{ml})$ contained $100 \mu \mathrm{mol}$ Tris buffer $(\mathrm{pH}$ 7.8), $7.5 \mu \mathrm{mol} \mathrm{MgSO}_{4}, 0.1 \mu \mathrm{mol}$ acetyl-CoA, $20 \mu \mathrm{mol}$ $\mathrm{KHCO}_{3}, 0.15 \mu \mathrm{mol} \mathrm{NADH}, 12 \mathrm{U}$ malate dehydrogenase (Sigma), $10 \mu \mathrm{mol}$ potassium pyruvate, and cell-free extract. The reaction was started with addition of 4 $\mu \mathrm{mol}$ ATP. The activity was measured at $340 \mathrm{~nm}$.

The fumarase activity produced with L-malic acid as the substrate was determined by measuring L-malic acid (50 mM) consumption at $250 \mathrm{~nm} \mathrm{[28].} \mathrm{The} \mathrm{fumarase}$ activity with fumaric acid as the substrate was assayed under the same conditions and by following the decrease in absorbance at $300 \mathrm{~nm}$ that occurs when fumaric acid is converted to L-malic acid.

All enzyme assays were performed at $30^{\circ} \mathrm{C}$ with freshly prepared extracts. Total protein concentration was measured by the Lowry method [29], using bovine serum albumin as the standard.

\section{Transcriptional analysis}

For RNA extraction, early-stationary phase cells from flask culture were harvested by centrifugation $(8000 \mathrm{rpm}$ at $4^{\circ} \mathrm{C}$ for $5 \mathrm{~min}$ ), and stored at $-80^{\circ} \mathrm{C}$ until use. Total RNA was extracted with the RNAprep pure Plant Kit following the manufacturer's instructions. cDNA was synthesized from total RNA by using the PrimeScript ${ }^{\circledR}$ RT reagent kit Perfect Real Time (TaKaRa Biotechnology Co., Ltd.) according to the manufacturer's protocol. Quantitative real-time PCR was performed in a $25 \mu \mathrm{l}$ (total volume) mixture containing $12.5 \mu \mathrm{l}$ of SYBR ${ }^{\circledR}$ Premix Ex Taq $^{\mathrm{TM}}$ II $(2 \times), 400 \mathrm{nmol}$ each of forward and reverse primers, and $2 \mu \mathrm{l}$ of the cDNA sample. Primers used in the transcriptional analysis are listed in Table 5, and the $\beta$-ACTIN gene was used as the internal control. Amplification and detection of specific products were performed with a Light Cycler $^{(} 480$ (Roche, Basel, Switzerland). The detection profile used was: incubation at $95^{\circ} \mathrm{C}$ for $30 \mathrm{~s}, 40$ cycles at $95^{\circ} \mathrm{C}$ for $5 \mathrm{~s}, 60^{\circ} \mathrm{C}$ for $20 \mathrm{~s}$, and $50^{\circ} \mathrm{C}$ for $30 \mathrm{~s}$. Data analysis was performed using

Table 5 Primers used in the transcriptional analysis

\begin{tabular}{lll}
\hline Primer & Sequences, 5'-3' $^{\prime}$ & Analyzed gene \\
\hline F(RoMDH $)$ & CGCTGCTGGTGGTATGG & RoMDH \\
R(RoMDH) & TGGAGTTGGTTGATGTGG & \\
F(RoFUM1) & AAGGCTGCTGCTACTGTC & RoFUM1 \\
R(RoFUM1) & CACGGTTGAGATAACTTCG & \\
F(PYC2) & AGAGGTGAGATTCCGATTAG & PYC2 \\
$R(P Y C 2)$ & GTCCATTGCCAAGTAAGC & \\
$F(A C T)$ & AGGTATTGCCGAAAGATGC & $\beta$-ACTIN \\
$R(A C T)$ & CTTGTGGTAACGATAGATGG & \\
\hline
\end{tabular}


the second derivative method. Each sample was tested in triplicate in a 96-well plate (Bio-Rad). To calculate the relative expression level of the target genes, a relative standard curve method was used. The expression ratio was obtained by dividing the relative expression level of the mutant strain by that of the control strain.

\section{Acknowledgements}

This work was supported by grants from the Major State Basic Research Development Program of China (973 Program, No. 2007CB714306), the Key Program of National Natural Science Foundation of China (No. 20836003), and the national outstanding doctorate paper author special fund (No. 200962), Program for New Century Excellent Talents in University (NCET-100456), A Project Funded by the Priority Academic Program Development of Jiangsu Higher Education Institutions, and Doctor Candidate Foundation of Jiangnan University (JUDCF09015).

\section{Author details}

'State Key Laboratory of Food Science and Technology, Jiangnan University, Wuxi 214122, China. ${ }^{2}$ The Key Laboratory of Industrial Biotechnology, Ministry of Education, School of Biotechnology, Jiangnan University, Wuxi 214122, China. ${ }^{3}$ The Key Laboratory of Carbohydrate Chemistry and Biotechnology, Ministry of Education, School of Biotechnology, Jiangnan University, Wuxi 214122, China

\section{Authors' contributions}

GQX has made contribution to the design of the experiments, the acquisition of data, the analysis and interpretation of data and has contributed to the writing of the manuscript. LML and JC conceived and organized the study and helped to draft the manuscript, and have revised the manuscript. All the authors have read and given their final approval of the version to be published.

\section{Competing interests}

The authors declare that they have no competing interests.

Received: 14 September 2011 Accepted: 15 February 2012 Published: 15 February 2012

\section{References}

1. Werpy T, Petersen G: Top value added chemicals from biomass, vol.I. Results of screening for potential candidates from sugars and synthesis gas. US Department of Energy, Washington, DC 2004 [http://dx.doi.org/ 10.2172/15008859]

2. Raab AM, Gebhardt G, Bolotina N, Weuster-Botz D, Lang C: Metabolic engineering of Saccharomyces cerevisia for the biotechnological production of succinic acid. Metab Eng 2010, 12:518-525.

3. Ichikawa S, lino T, Sato S, Nakahara T, Mukataka S: Improvement of production rate and yield of fumaric acid from maleic acid by heat treatment of Pseudomonas alcaligene strain XD-1. Biochem Eng J 2003, 13:7-13.

4. Engel CAR, Adrie J, Straathof J, Zijlmans TW, van Gulik WM, Wielen LAMvd: Fumaric acid production by fermentation. Appl Microbiol Biotechnol 2008 78:379-389.

5. Nevoigt E: Progress in metabolic engineering of Saccharomyces cerevisia. Microbiol Mol Biol Rev 2008, 72:379-412.

6. Goffeau A: Four years of post-genomic life with 6,000 yeast genes. FEBS Lett 2000, 480:37-41.

7. Nielsen J: Systems biology of lipid metabolism: from yeast to human. FEBS Lett 2009, 583:3905-3913.

8. van Maris AJA, Geertman JMA, Vermeulen A, Groothuizen MK, Winkler AA, Piper MDW, van Dijken JP, Pronk JT: Directed evolution of pyruvate decarboxylase-negative Saccharomyces cerevisia, yielding a C-2independent, glucose-tolerant, and pyruvate-hyperproducing yeast. Appl Environ Microbiol 2004, 70:159-166.

9. Tokuhiro K, Ishida N, Nagamori E, Saitoh S, Onishi T, Kondo A, Takahashi H: Double mutation of the $P D C$ and $A D H$ genes improves lactate production in the yeast Saccharomyces cerevisia expressing the bovine lactate dehydrogenase gene. Appl Microbiol Biotechnol 2009, 82:883-890.

10. Zelle RM, de Hulster E, van Winden WA, de Waard P, Dijkema C, Winkler AA, Geertman J-MA, van Dijken JP, Pronk JT, van Maris AJA: Malic acid production by Saccharomyces cerevisia: engineering of pyruvate carboxylation, oxaloacetate reduction, and malate export. Appl Environ Microbiol 2008, 74:2766-2777.

11. Zelle RM, De Hulster E, Kloezen W, Pronk JT, van Maris AJA: Key process conditions for production of $C(4)$ dicarboxylic acids in bioreactor batch cultures of an engineered Saccharomyces cerevisia strain. Appl Environ Microbiol 2010, 76:744-750.

12. Abbott DA, Zelle RM, Pronk JT, van Maris AJA: Metabolic engineering of Saccharomyces cerevisia for production of carboxylic acids: current status and challenges. FEMS Yeast Res 2009, 9:1123-1136.

13. Pines O, Even-Ram S, Elnathan N, Battat E, Aharonov O, Gibson D, Goldberg l: The cytosolic pathway of L-malic acid synthesis in Saccharomyces cerevisia: the role of fumarase. Appl Microbiol Biotechnol 1996, 46:393-399.

14. Stein I, Peleg Y, Even-Ram S, Pines O: The single translation product of the FUM1 gene (fumarase) is processed in mitochondria before being distributed between the cytosol and mitochondria in Saccharomyces cerevisia. Mol Cell Biol 1994, 14:4770-4778.

15. Karniely S, Regev-Rudzki N, Pines O: The presequence of fumarase is exposed to the cytosol during import into mitochondria. J Mol Biol 2006, 358:396-405.

16. Yogev O, Karniely S, Pines O: Translation-coupled translocation of yeast fumarase into mitochondria in vivo. J Biol Chem 2007, 282:29222-29229.

17. Regev-Rudzki N, Yogev O, Pines O: The mitochondrial targeting sequence tilts the balance between mitochondrial and cytosolic dual localization. Cell Sci 2008, 121:2423-2431.

18. Regev-Rudzki N, Battat E, Goldberg I, Pines O: Dual localization of fumarase is dependent on the integrity of the glyoxylate shunt. Mol Microbiol 2009, 72:297-306.

19. Kenealy W, Zaady E, du Preez JC, Stieglitz B, Goldberg I: Biochemical aspects of fumaric acid accumulation by Rhizopus arrhizu. Appl Environ Microbiol 1986, 52:128-133.

20. Peleg Y, Battat EC, Scrutton M, Goldberg I: Isoenzyme pattern and subcellular localisation of enzymes involved in fumaric acid accumulation by Rhizopus oryza. Appl Microbiol Biotechnol 1989, 32:334-339.

21. Minard Kl, McAlister-Henn L: Glucose-induced degradation of the MDH2 isozyme of malate dehydrogenase in yeast. J Biol Chem 1992, 267:17458-17464.

22. McAlister-Henn L, Steffan JS, Minard Kl, Anderson SL: Expression and function of a mislocalized form of peroxisomal malate dehydrogenase (MDH3) in yeast. J Biol Chem 1995, 270:21220-21225.

23. Vemuri GN, Eiteman MA, McEwen JE, Olsson L, Nielsen J: Increasing NADH oxidation reduces overflow metabolism in Saccharomyces cerevisia. Proc Natl Acad Sci USA 2007, 104:2402-2407.

24. Flikweert MT, Van Der Zanden L, Janssen WM, Steensma HY, Van Dijken JP, Pronk JT: Pyruvate decarboxylase: an indispensable enzyme for growth of Saccharomyces cerevisia on glucose. Yeast 1996, 12:247-257.

25. Hohmann S, Meacock PA: Thiamin metabolism and thiamin diphosphatedependent enzymes in the yeast Saccharomyces cerevisia: genetic regulation. Biochim Biophys Acta 1998, 1385:201-219.

26. Sikorski RS, Hieter P: A system of shuttle vectors and yeast host strains designed for efficient manipulation of DNA in Saccharomyces cerevisia. Genetics 1989, 122:19-27.

27. de Jong-Gubbels P, Vanrolleghem P, Heijnen S, van Dijken JP, Pronk JT: Regulation of carbon metabolism in chemostat cultures of Saccharomyces cerevisia grown on mixtures of glucose and ethanol. Yeast 1995, 11:407-418.

28. Kanarek L, Hill RL: The preparation and characterization of fumarase from swine heart muscle. J Biol Chem 1964, 239:4202-4206.

29. Lowry OH, Rosebrough NJ, Farr AL, Randall RJ: Protein measurement with the Folin phenol reagent. J Biol Chem 1951, 193:265-275.

doi:10.1186/1475-2859-11-24

Cite this article as: Xu et al:: Reconstruction of cytosolic fumaric acid biosynthetic pathways in Saccharomyces cerevisiae. Microbial Cell

Factories 2012 11:24. 